\title{
Documentários Científicos sobre o Mundo Natural no Ensino de Biologia
}

\author{
Scientific Documentaries on Nature in the Biology Teaching
}

Jennifer Caroline de Sousa'

'Universidade de São Paulo (USP), Faculdade de Educação (FE), São Paulo, SP, Brasil. E-mail: jennifercsousa@usp.br

Resumo: Filmes documentários são frequentemente recomendados como recursos didáticos para aulas de Ciências e Biologia. Contudo, pouco é examinado sobre como essa linguagem audiovisual pode ser explorada na prática educativa dessas disciplinas. Tomando como objetos de análise os documentários Nascido do fogo, da série Galápagos, produzida pela BBC, e Explosão da vida, da coleção Origens da vida produzida pela National Geographic, neste trabalho buscou-se identificar e analisar as concepções de ciência e natureza neles presentes e avaliar potencialidades e limites de seu emprego no ensino de Biologia. A partir da análise do conteúdo verbal dos filmes, observou-se que ambos apresentam uma imagem idealizada da ciência e um senso fortemente estético sobre a natureza. Tais elementos podem fomentar discussões acerca da natureza da ciência $(\mathrm{NdC})$ e de conteúdos relacionados às áreas de Evolução, Ecologia e Zoologia, dentro de uma abordagem crítica e interdisciplinar.

Palavras-chave: Ensino de biologia; Ensino de ciências; Material didático; Filme documentário; Natureza da ciência.

Abstract: Documentary films are usually recommended as didactic resources for Science and Biology classes. Nevertheless, it is yet to be examined how this audiovisual language could be explored in these subjects. Taking as objects of investigation the documentaries Born of fire, of Galapagos series, produced by BBC and Shape of life, belonging to Origins of life collection produced by National Geographic, in this study it was identified and analyzed the documentaries' science and nature conceptions and evaluated potentialities and limits of their use in the Biology Teaching. From analysis of films' verbal content, it was observed that both documentaries expressed an idealized image of science and a perspective strongly aesthetic about nature. These elements may instigate debates about nature of science (NoS) and contents related to Evolution, Ecology and Zoology fields from a critical and interdisciplinary approach.

Keywords: Biology teaching; Science teaching; Teaching material; Film documentary; Nature of science.

Recebido em: 12/03/2019

Aprovado em: 07/08/2019 


\section{Introdução}

Embora ainda seja notável a centralidade da escrita na prática educativa (BRENNAND, 2008), há algum tempo tem sido contestada a incorporação de outros tipos de linguagens no trabalho escolar. A Lei no 13.006, de 26 de junho de 2014 (BRASIL, 2014), acrescentou a redação de um artigo na Lei de Diretrizes e Bases da Educação Nacional (Lei no 9394/96) (BRASIL, 1996) que instituiu a obrigatoriedade da exibição de, no mínimo, 2 horas mensais de filmes de produção nacional nas escolas de Educação Básica.

Esforços nesse sentido também ocorreram no estado de São Paulo com a implementação do projeto 'O cinema vai à escola: o uso da linguagem cinematográfica na educação' no ano de 2008, que consistiu no envio de filmes selecionados por especialistas e na elaboração dos Cadernos de cinema do professor, um material de apoio para orientar os docentes na incorporação da linguagem cinematográfica em suas aulas (SÃO PAULO, 2008).

Para Napolitano (2009), trabalhar com o cinema na escola envolve duas premissas. A primeira delas se refere à concepção da natureza de representação e da encenação cinematográfica. Qualquer filme, seja ficcional ou não-ficcional, é resultado de seleções, recortes, ângulos, pontos de vista que congregam uma gama de profissionais e de interesses comerciais, ideológicos e estéticos. Essa afirmação, por sua vez, tem subjacente a ideia de que filmes documentais não representam diretamente a realidade e que filmes ficcionais não estão desligados da sociedade que os produziu.

A segunda prerrogativa, segundo o autor, é a compreensão do cinema como uma linguagem artística, em que assistir a um filme signifique uma experiência estética e cultural, formativa em si e por si. Dessa forma, é esperado que a sua incorporação às atividades pedagógicas não tenha caráter meramente ilustrativo ou casual.

Entretanto, diferentemente das disciplinas de ciências humanas que têm explorado o cinema como recurso didático e documento de análise (NAPOLITANO, 2009), no âmbito das ciências naturais este recurso ainda representa uma temática de investigação pouco expressiva nas publicações acadêmicas da área de Ciência e Educação (MARCELLO; RIPOLL, 2016). No caso do ensino de Biologia, Teixeira e Megid Neto (2012) constataram que nenhuma tese ou dissertação defendida até o ano de 2004 no Brasil se dedicou à análise de como documentários e programas com temáticas associadas à Biologia, disponíveis nos formatos VHS, CD, DVD etc., são empregados pelos professores no contexto das aulas, e que impactos esses recursos produzem em termos de aprendizagem.

Ainda que se possa afirmar como escassa a pesquisa acadêmica em torno desse tema, a presença de filmes na prática educativa em Ciências é recorrente (MARCELLO; RIPOLL, 2016; TEIXEIRA; MEGID NETO, 2012). Contudo, Borba (2017) salienta que dificilmente as aulas de Ciências e Biologia enfatizam as possibilidades artísticas e criativas abertas por essas produções cinematográficas. Ademais, Bruzzo (1998) pontua que, frequentemente, o gênero documentário é eleito pelos professores por apresentar uma 'finalidade pedagógica' explícita com seu discurso 'sério' e 'científico'.

Na contramão dessa perspectiva, Díaz eWaldegg (2004) afirmam que os'documentários científicos' operam representações audiovisuais da ciência que necessitam ser estudadas no âmbito escolar. Para Tucherman e Ribeiro (2006), o que justifica essa preocupação é o fato de que a educação formal na área de Ciências Naturais é confrontada com a expectativa que os meios de comunicação trazem sobre a ciência, esta que, não raro, é apresentada de forma caricatural, o que, muitas vezes, obscurece o discurso social subjacente a essa visão. 
Nesse sentido, algumas questões balizam a discussão aqui proposta: que imagens de ciência e de natureza esses documentários buscam construir nos espectadores? Documentários desse gênero podem contribuir para o ensino de Ciências e Biologia? De que forma? O que um professor poderia levar em consideração para escolher um determinado documentário e que orientações seriam interessantes para tornar essa experiência mais frutífera em termos educacionais?

Tomando-as como ponto de partida, estabelecemos como objetivo deste trabalho problematizar o uso de documentários científicos sobre o mundo natural como recurso didático no ensino de Biologia. Para tanto, foram analisadas duas obras: Nascido do fogo (Born of fire, no título original), da série Galápagos (2004) produzida pela British Broadcasting Corporation (BBC) e Explosão da vida (Shape of life, no título original), da coleção Origens da vida (2005) produzida pela National Geographic.

A escolha de ambas se deu, primeiramente, pela tradição que as empresas BBC e National Geographic possuem no ramo da indústria documentária sobre a natureza, cujas produções são facilmente encontradas em espaços domésticos e educacionais (BORBA, 2017), a exemplo da série Galápagos (2004) emprestada da videoteca de uma escola estadual paulista. Segundo, esses documentários abordam temáticas diretamente relacionadas ao currículo prescritivo da disciplina de Biologia, que permitem inferir as concepções de ciência e de natureza por eles assumidas.

Ademais, como será argumentado ao longo deste texto, ambos os documentários operam dentro de um modo predominantemente expositivo, o qual, segundo Nichols (2005), é a forma básica que ainda permanece em documentários televisivos, noticiários noturnos, em filmes sobre natureza e ciência, biografias e documentários históricos. Com sua origem na década de 1920, o documentário expositivo ainda exerce grande influência nas produções atuais, o que nos sugere que as obras aqui analisadas podem ser tomadas como representativas desse estilo. Com isso, não se advoga para que sejam elas estritamente empregadas em sala de aula, mas que possam aventar o exercício analítico de outros filmes estilisticamente semelhantes.

O texto deste artigo está orientado da seguinte forma: inicialmente, é apresentado um breve panorama sobre a linguagem audiovisual dos documentários ou, em sentido mais amplo, os filmes não-ficcionais. A referência principal é Bill Nichols, teórico e crítico de cinema que ao longo de sua carreira contribuiu de forma significativa para o campo, inaugurando o estudo contemporâneo dos documentários na década de 1980. A partir de sua obra Introdução ao documentário (NICHOLS, 2005) traduzida para o português em 2005, são descritos alguns conceitos centrais de sua tese: as 'vozes do documentário' e seus 'modos de representação'. Dessa forma, à luz da teoria de Nichols, buscou-se realizar a leitura dos documentários selecionados para este trabalho.

Em seguida, é encaminhada a análise dos filmes mencionados, que contou com a metodologia da Análise de Conteúdo (AC), definida por Bardin (2016) como um conjunto de técnicas múltiplas e multiplicadas cujo objetivo comum é a interpretação de uma mensagem através de um processo dedutivo, isto é, a partir de inferências. Essas permitem conhecer as condições de produção (e, eventualmente, de recepção) das mensagens e, independente da forma como são obtidas, contribuem para que se regresse às causas ou se desça aos efeitos das características das comunicações. Na AC, portanto, o interesse é expor o conteúdo latente, escondido, não aparente, retido por qualquer mensagem. 
Seguindo as fases da AC proposta por Bardin (2016), iniciou-se a pré-análise dos documentários através de sua leitura flutuante, que, após serem assistidos mais de uma vez, tiveram o seu conteúdo (conjunto de mensagens verbalizadas pelo narrador em voz over e pelos cientistas entrevistados) integralmente transcrito a partir das legendas em português. As imagens associadas às falas foram descritas durante o processo de transcrição como recurso para constituição das unidades de contexto. Embora os documentários possuam uma significativa pluralidade de códigos (linguístico, icônico e semiótico) e suportes nas mensagens veiculadas, é sabido também que a AC conserva como terreno privilegiado de análise o código linguístico (BARDIN, 2016). Por isso, neste trabalho exploramos a associação entre imagens, sons e falas ao longo de nossa retórica argumentativa utilizando da linguagem escrita.

A partir da leitura flutuante, buscou-se identificar e analisar quais e como se manifestam as concepções de ciência e natureza em Nascido do fogo (2004) e Explosão da vida (2005) e avaliar potencialidades e limites desse tipo de mídia audiovisual como ferramenta de aprendizagem de conceitos biológicos. Dessa forma, se avançou à segunda etapa da AC que consistiu da exploração do material. Para tanto, este estudo se valeu da modalidade de AC denominada análise temática. Bardin (2016, p. 135) afirma que "o tema é geralmente utilizado como unidade de registro para estudar motivações de opiniões, de atitudes, de valores, de crenças, de tendências etc.". Minayo (2010) acrescenta que a noção de 'tema' está relacionada à afirmação sobre determinado assunto e, normalmente, é apresentada através de uma palavra, uma frase ou de um resumo. Tendo isso em vista, os textos provenientes da transcrição das falas de cada um dos documentários foram fragmentados em pequenos excertos e analisados de modo transversal, ou seja, segundo os temas-objeto de análise (ou seja, as concepções de "natureza" e "ciência" e os conceitos biológicos das áreas da Biologia abarcadas pelos documentários), independente do momento em que a afirmação teve lugar.

Por fim, a terceira e última etapa da $A C$ que se refere à inferência e interpretação dos resultados foi realizada à luz de referenciais associados às áreas do cinema documental, da História e Filosofia da Ciência e do Ensino de Biologia.

\section{Breve Revisão sobre o Cinema-Documentário}

O documentário tem suas raízes históricas no cinema (CARVALHO, 2006) e, segundo Torres (2011), teria surgido como oposição à ficção, com objetivo de dar a conhecer aspectos factuais do mundo real. Dessa forma, se apresentaria como um filme de 'não-ficção', um 'editorial' ou um 'ponto de vista' do documentarista sobre a realidade crua, podendo essa produção, no entanto, contar com 'elementos de ficção' frente à necessidade, por parte do autor, de reconstruir um fato por ele não presenciado. Com relação a esse último aspecto, Marcello (2010) considera que o documentário talvez revele, de forma mais pontual, a dualidade entre o 'real' e a 'ficção', tensionando, inclusive, o próprio conceito de 'ficção' ao afirmar-se como seu oposto.

O rótulo do documentário, como discute Carvalho (2006), é utilizado para classificar uma gama de filmes e vídeos, cuja diversidade se expressa a partir da variedade de métodos, tendências, estilos e técnicas que apresentam.

Nichols (2005) descreve que os documentários, ainda que possam apresentar a narração de histórias tipicamente presente em filmes de ficção comuns, compartilham certas ênfases que nos permitem discuti-los como um gênero próprio: (i) a existência de uma lógica 
de organização baseada numa retórica; (ii) a "montagem de evidência", que se refere à sequência de cenas construída para trazer a impressão de um argumento único, convincente, sustentado por uma lógica; e, (iii) o papel de destaque para o discurso voltado ao espectador.

Marcello (2010) alerta que atualmente essa caracterização tem sofrido um duplo movimento de crítica e relativização, sobretudo com o surgimento de novos documentários e invenções. No entanto, como será mostrado mais a frente, ambos os filmes analisados neste estudo se vinculam fortemente a uma concepção mais clássica das características gerais de um documentário, tal como postula Nichols (2005). Dessa forma, optou-se por explicitar de modo mais detalhado apenas as categorias analíticas pertencentes à tradição de pensamento desse teórico.

Nichols (2005) discute que os documentários reúnem provas e as utilizam para construir uma perspectiva ou argumento sobre o mundo, seja de forma poética ou retórica, para o mundo. Todavia, ele identifica a "voz do documentário" como elemento central para a abordagem desse tipo de produção e explica que essa voz não se limita ao que é falado literalmente pelo narrador e/ou entrevistados nos documentários, embora a palavra dita desempenhe papel crucial na maioria deles.

Bonotto (2009) resume que a voz do documentário seria a reunião dos recursos imagéticos e sonoros articulados no documentário para se dirigir ao espectador. CarmoRoldão, Bazi e Oliveira (2007) enumeram na obra de Nichols quatro meios de constituição de voz: (i) a construção imagética; (ii) o som; (iii) a cronologia dos eventos; e, (iv) modo de representação.

Os autores explicam que a construção imagética se refere às seleções de imagens feitas pelo documentarista, o que inclui os ângulos, os enquadramentos, a movimentação da câmera, o uso dos filtros, lentes etc., além do emprego de imagens de arquivos, filmes e fotografias. Em relação ao som, muito da persuasão do documentário vem da trilha sonora, podendo ela, em alguns casos, ajudar a compor a narrativa (música diegética) ou produzir novas linguagens. Já a cronologia dos eventos se relaciona ao tempo de duração do filme, dos planos, e contribui para a sustentação do argumento. Por fim, os modos de representação, na conceituação de Nichols, funcionam como subgêneros do documentário. Carmo-Roldão, Bazi e Oliveira (2007) os traduzem como sendo tipos de posturas metodológicas adotadas diante da realidade e Molfetta (2008) os interpreta como um conjunto de regras que modulam a construção do espaço, do tempo e da enunciação do relato audiovisual.

Seis modos de representação são descritos por Nichols (2005): poético, expositivo, participativo, observativo, reflexivo e performático. Eles teriam aparecido com a evolução dos filmes documentários e estão ligados à determinação de uma estrutura de afiliação frouxa, havendo, em muitos casos, a sobreposição e a mistura de modos em um mesmo documentário, embora frequentemente se observe a predominância de algum deles na organização do filme.

O modo de representação poético enfatiza a subjetividade, explora associações e padrões que envolvem ritmos temporais e justaposições espaciais e raramente os atores sociais são personagens de complexidade psicológica e de visão de mundo definida. Assim, o que se valoriza mais é o estado de ânimo, o tom, o afeto do que a exposição de conhecimentos através de ações persuasivas. Carmo-Roldão, Bazi e Oliveira (2007) indicam que esse modo prioriza mais os planos e as impressões do documentarista a respeito do assunto tratado. 
O modo de representação expositivo dirige-se ao espectador diretamente, com legendas ou comentários de um narrador anônimo com 'voz de Deus' que descreve uma situação ou problema, propõe uma perspectiva, expõe um argumento ou reconta uma história, às vezes, evocando um tom de ânimo poético. Carmo-Roldão, Bazi e Oliveira (2007) apontam que a preocupação se concentra na defesa de argumentos mais do que com a estética e/ou a subjetividade, trazendo como marca a objetividade através do casamento entre o 'dito' e o 'mostrado'. São exemplos os documentários produzidos pela Discovery Channel, BBC, National Geographic que, segundo Molfetta (2008, p. 20) expressam "[...] em síntese, a estética naturalista, o cinema como Janela para o Mundo".

O modo de representação participativo é, segundo Carmo-Roldão, Bazi e Oliveira (2007), caracterizado pela participação ativa do documentarista e sua equipe no documentário. A presença deles se evidencia nas conversas com os entrevistados, reforçando a interação entre os produtores e o tema. Nichols (2005, p. 154) discute que ao ver um documentário participativo, o espectador espera "[...] testemunhar o mundo histórico da maneira pela qual ele é representado por alguém que nele se engaja ativamente, e não por alguém que observa discretamente, reconfigura poeticamente ou monta argumentativamente esse mundo".

O modo de representação observativo, descrevem Carmo-Roldão, Bazi e Oliveira (2007), concebe o documentarista praticamente como voyeur que somente observa sem interferir para evitar qualquer falseamento da realidade. A ideia é mostrar a vida tal como é vivida a fim de "[...] nos dar a sensação de como é estar em uma determinada situação, mas sem a noção do que é, para o cineasta, estar lá também" (NICHOLS, 2005, p. 153, grifo do autor). O isolamento do documentarista como observador frente à interação dos atores sociais que praticamente o ignoram, delega ao espectador uma postura mais ativa na determinação da importância do que se diz e se faz.

O modo de representação reflexivo é discriminado, segundo Nichols (2005), pela relação que o documentarista estabelece com o espectador no sentido em que o objetivo do documentário não é mais apenas falar do mundo histórico, mas também com o espectador sobre problemas e questões de representação. Portanto, a subjetividade e reflexividade são fortemente enfatizadas e, como acrescentam Carmo-Roldão, Bazi e Oliveira (2007), os procedimentos da filmagem e a relação entre grupo filmado e documentarista se tornam evidentes para o espectador que consegue notar a reação dos entrevistados diante da câmera e de seu realizador.

Por fim, o modo de representação performático é caracterizado, nos contam CarmoRoldão, Bazi e Oliveira (2007), também pela subjetividade e pelo padrão estético adotado, aproximando-se dos filmes do tipo vídeo-arte, cinema experimental e de vanguarda por utilizar técnicas cinematográficas de maneira livre. A respeito desse último aspecto, Nichols (2005) salienta que o documentário de modo performático enfatiza menos a característica independente do filme e, semelhantemente ao modo poético, destaca a complexidade do nosso conhecimento do mundo no tocante às suas dimensões subjetivas e afetivas, diminuindo o compromisso com a representação realista do mundo histórico ao assumir licenças poéticas.

Na história dos documentários, Borba (2017) conta que o gênero 'documentário de natureza' teria surgido com programas televisivos sobre natureza criados pela unidade de História Natural da BBC estabelecida em Bristol no ano de 1957. Na década de 1980 empresas como a Discovery Communications, nos EUA, e a BBC, no Reino Unido, se estabeleceram e criaram canais próprios de TV por assinatura, cuja programação destinou-se, basicamente, 
à exibição de documentários, séries e programas educativos sobre ciência, tecnologia, história, meio ambiente e geografia. Em 1997, a National Geographic, fruto da organização National Geographic Society criada em 1888 em Washington por estudiosos e especialistas de diferentes áreas, lançou seu próprio canal, o National Geographic Channel. Atualmente, o canal em high definition (HD) NatGeo Wild exibe somente filmes e programas sobre a natureza.

A autora menciona que os documentários produzidos pela Discovery, BBC e National Geographic possuem um reconhecimento popular bastante consolidado, os quais empregam cada vez mais tecnologias de imagem e de comunicação para popularizar conteúdos científicos e torná-las atraentes e acessíveis para serem utilizados em espaços escolares, universitários e domésticos. Além disso, ganham maior visibilidade e legitimidade ao circularem pelas grandes corporações midiáticas e trazerem cientistas e celebridades para apresentar e embasar seu conteúdo.

Para Bruzzo (1998), a aparente propensão a atribuir menor importância na análise de mídias que girem em torno de temas envolvendo a atividade científica ou o mundo natural pode ser explicada, talvez, pela relação ambígua que a sociedade mantém com tudo que guarde ligação com a ciência: uma espécie de misto de respeitoso temor e distanciamento com a consideração ingênua de que a esfera científica seja menos interessante ou mereça menos atenção.

Investigar as estratégias de que se valem essas produções para produzir suas'verdades' a respeito do mundo natural e científico não significa afirmar peremptoriamente que eles mintam ou enganem. Trata-se de denotar como os documentários operam para que 'algo seja tido como tal' (MARCELLO; RIPOLL, 2016). Nesse sentido, é preciso salientar que o intuito deste trabalho não é o de caracterizar o que efetivamente é 'verdadeiro' ou não nos filmes selecionados. O que se busca é identificar as concepções de natureza e ciência presentes e de que forma elas se expressam nas relações estabelecidas entre as 'vozes' dos documentários. A partir daí, tencionamos qualificar como essa linguagem audiovisual dos documentários científicos pode ser explorada para a aprendizagem em Biologia.

\section{As Ilhas Galápagos sob as Lentes de Nascido no Fogo}

Nascido do fogo (2004) explora as Ilhas Galápagos dando ênfase à história de formação do arquipélago, à sua dinâmica geológica e aos seres vivos - sobretudo, animais - que ali habitam. O filme conta com um repertório singular e exuberante de imagens das Ilhas captadas por equipamentos de alta resolução e definição. Sua sonoplastia consegue, simultaneamente, harmonizar-se com os outros elementos do documentário (como o universo imagético, narrador em voz over) e constituir-se como uma narrativa em si haja vista sua trilha sonora marcadamente épica.

O documentário inicia-se com a exibição de uma imagem de um oceano a perder de vista no horizonte e uma música épica de fundo. Em sobreposição a uma sequência de imagens do ambiente natural do arquipélago, uma narradora surge, com um timbre tranquilo e suave, indicando posicionamento geográfico das Ilhas e evidenciando as primeiras noções sobre esse ambiente natural: "um mundo perdido na vastidão do Pacífico" cuja natureza é "lar da vida mais estranha e inimaginável, governada pelas forças brutais da natureza". 
Tais expressões imprimem a ideia de um ambiente praticamente 'imaculado' porque desconhecido e hostil aos humanos e, nesse sentido, as Ilhas constituem-se num 'outro geográfico' (MORAES, 2001), pois sua localização tida como 'distante', 'isolada', traduz o estranhamento geográfico que os humanos têm em relação a esse ambiente.

O vínculo entre a descrição geográfica e a emissão de juízos de valor prossegue ao longo do documentário, que frequentemente expressa uma espécie de incredulidade pela existência de vida em um ambiente como Galápagos, ainda que, de modo paradoxal, seja mencionada a diversidade de seres animais que transitam pelas Ilhas.

Rezende (2008) assevera que a maneira como um documentarista organiza as histórias, os argumentos que intenciona contar e as imagens e os indivíduos que deseja mostrar refletem um conjunto de valores e ideias específicos do qual ele compartilha. Sendo assim, Borba (2017, p. 3) afirma que "[...] ver animais, plantas e fenômenos naturais nos filmes documentais não pode ser equiparado a uma suposta expressão exata, natural e definitiva"

A ideia de 'provação para a vida' que Nascido do Fogo (2004) concebe para a relação entre o ambiente físico e os seres vivos nativos também se estende para os humanos: " $A$ primeira pessoa que pisou nas Galápagos orou apenas pela libertação desse lugar deplorável. Nos séculos que se seguiram, todos que vieram aqui partilharam da mesma opinião". No entanto, a ruptura com essa perspectiva se dá com a menção à chegada do naturalista Charles Darwin (1809-1882) na ocasião de sua viagem no navio HMS Beagle (1831-1836): "Mas com o tempo, um homem inspirado pela paisagem e vida selvagem, viu as coisas de uma maneira diferente, descobrindo um segredo escondido nessa ilha, nesse universo. Um segredo que iria transformar não apenas como enxergamos essas ilhas, mas toda a nossa compreensão de vida na Terra. Seu nome era Charles Darwin".

Com isso, o documentário sugere a adoção de uma estética atrelada ao que se poderia descrever como 'ideologia civilizatória'. A presença de Darwin, que denota uma agência fundacional e civilizatória a partir do olhar da ciência, faz com que as Galápagos sejam agora encaradas como "ilhas que mudaram nossa compreensão da vida na Terra".

A cientificidade do filme se expressa, portanto, a partir de dois elementos principais: (1) pelo requerimento de ciência na figura desse naturalista famoso que 'revelou' as Galápagos para o mundo; e, (2) pela apresentação de uma série de dados precisos conjugada às explicações científicas sobre as características e fenômenos do arquipélago e a ecologia das espécies residentes. Além disso, toda exposição é mediada por uma narradora com 'voz de Deus', cujo tom ameno e ausente em determinados momentos induz o espectador a conceber uma suposta neutralidade sobre o que se está veiculando.

Como afirma Nichols (2005), a racionalidade informativa que pauta a construção desse tipo de documentário normalmente trabalha com um modelo do tipo 'solução de problemas', em que uma temática é abordada dentro de um estilo pergunta-resposta. Em Nascido do fogo (2004), essa construção é observada, por exemplo, nessa passagem: "Ela está bem acima do hot spot vulcânico no extremo oeste do arquipélago. Mas como é que as outras ilhas, criadas no mesmo hot spot, estão agora espalhadas a centenas de quilômetros ao leste? Todas as ilhas estão se movendo. Elas estão viajando para o sudeste, cerca de $2 \mathrm{~cm}$ por ano em uma grande placa tectônica que desliza continuamente sobre o hot spot. Suas jornadas começam assim que elas nascem. Enesse despertar, surgem novas ilhas. É como uma esteira rolante geográfica. Então, o arquipélago que vemos hoje vira uma foto instantânea com o tempo. As ilhas mais antigas estão a leste, as mais jovens a oeste. E conforme a Fernandina fica mais velha, ela será carregada nessa esteira rolante até o local onde hoje se encontram as maiores ilhas das Galápagos. 
Todas as ilhas seguirão esse curso, carregadas pela esteira rolante e terão o mesmo destino. Inúmeras Ilhas Galápagos vieram e se foram. Sempre foi assim, e sempre será".

Stocking (2005) afirma que normalmente as mídias lidam de duas maneiras com as alegações científicas: ou tornam a ciência mais exata do que ela é, ou fazem a ciência parecer incerta e desconcertante. O grau de certeza atribuíd à hipótese da esteira rolante geográfica mencionada no trecho indica que o documentário credita ao conhecimento científico um poder de explicação supostamente inquestionável.

Ainda que seja predominante o modo de representação do tipo expositivo em documentários de natureza (BORBA, 2017), em Nascido do fogo (2004) observa-se que os modos expositivo e poético se sobrepõem constantemente, fazendo com que tenham o mesmo peso a transmissão de informação e a mensagem de contemplação. Nesse sentido, é possível afirmar que o documentário não apenas se pretende informativo, mas objetiva um deleite artístico.

A trilha sonora que acompanha as cenas de uma natureza bela e exuberante contribui para a composição da narrativa, o que nos permitiria classificá-la como música diegética (CARMO-ROLDÃO; BAZI; OLIVEIRA, 2007). Por exemplo, a exibição de erupções vulcânicas ou da extensão das llhas está associada a uma canção de ritmo mais agressivo, agitado, enquanto que o nado acrobático de leões-marinhos ou o voo de aves são acompanhados por canções de ritmo mais brando, lento. Nesse sentido, é possível sugerir que a retórica que marca o documentário enaltece Galápagos a partir de uma perspectiva românticonaturalística, com forte tendência à valorização estética e contemplativa, tendo o humano como admirador e desbravador de sua natureza por meio da ciência.

Enquanto recurso didático, Nascido do fogo (2004) poderia fomentar uma abordagem interdisciplinar considerando, de imediato, a integração das disciplinas de Biologia e Geografia. No entanto, particularmente com relação à Biologia, duas grandes áreas se destacam no filme: Ecologia e Evolução.

Os conceitos de 'ecossistema' e 'biodiversidade' são apresentados no contexto de explicação sobre a dinâmica das correntes marítimas, a qual é descrita como propulsora da vida marinha nas Ilhas. Dessa forma, se estabelece uma relação de causalidade na explicação sobre a existência e sobrevivência dos seres vivos nativos. Além disso, a biodiversidade de espécies e a biodiversidade de comunidades são ilustradas quando se faz menção numericamente à quantidade de espécies ("mais de 500 espécies de peixe habitam essa água") e à coexistência de espécies distintas. Também os termos 'parentes' e 'ancestrais' indicam a referência à teoria evolutiva como modelo de explicação da existência de leões-marinhos e pinguins em uma região localizada próxima à linha do Equador.

O documentário segue apresentando a diversidade faunística de Galápagos e, sobre ela, ressaltam-se dois aspectos: relações ecológicas e sistema de acasalamento.

As relações ecológicas interespecíficas que recebem maior destaque são a predação e o mutualismo. Todos os exemplos citados pelo documentário - a relação entre atobás-de-patas-azuis e os peixes, e entre falcões e iguanas - podem ser utilizados didaticamente para discutir a predação como um fator importante na história evolutiva de espécies antagonistas (presa e predador, parasita e hospedeiro) (RICKLEFS, 2010).

Por outro lado, as relações mutualísticas entre as espécies são exemplificadas subentendendo-se a ocorrência de coevolução. A respeito disso, Ricklefs (2010) alerta que uma relação mutualística que observamos no momento atual não indica necessariamente 
que ela tenha se estabelecido pela evolução conjunta entre as duas espécies em interação.

Ademais, é possível notar em todos os exemplos de relações mutualísticas, a atribuição de algum grau de'consciência' ou voluntarismo aos animais. Com as afirmações "os caranguejos gostam de procurar algas parasitas e pele morta nesses iguanas", "Lagartos de lava, parentes distantes de répteis bem menores encontram uma maneira engenhosa de sobreviver nessa costa selvagem. Eles têm uma relação especial com os leões-marinhos" e "Apesar de sua grande armadura, as tartarugas são sensíveis a parasitas da pele. Elas não conseguem remover essas parasitas sozinhas. Então desenvolveram uma incrível relação com os tentilhões", os animais são antropomorfizados, como se suas ações na natureza fossem perpassadas por algum um tipo de racionalidade. Concebidos seus comportamentos como propositais, esses animais se tornam personagens no documentário.

Essa caracterização, por sua vez, também se evidencia quando se diz que "a família [de falcões] sincronizou a procriação para coincidir com essa farta oferta de comida". O casamento entre a sazonalidade do comportamento reprodutivo e o período de abundância de recursos alimentares é, segundo o documentário, resultante de uma 'escolha' deliberada dos falcões. Dessa forma, três aspectos podem ser questionados: (i) a não menção ao conceito de "seleção natural", que ocupa posição central na teoria evolutiva neodarwiniana (BRZOZOWSKI, 2006); (ii) a descaracterização da evolução como fenômeno que se dá sobre a população inteira e não sobre o indivíduo; e, (iii) a perspectiva teleológica presente na explicação do fenômeno de sincronização.

Vilela et al. (2012) argumentam que a teleologia é um princípio filosófico que entende a natureza como um sistema que relaciona meios e fins. Essa perspectiva, já há muito presente na história das Ciências, até hoje alimenta grandes debates no âmbito da comunidade acadêmica, sobretudo, das Ciências Biológicas, na qual há grande dissenso a respeito do tema.

Azevedo, Ayres e Selles (2013) comentam que, especialmente no caso do ensino de Evolução nas escolas, as explicações teleológicas dos fenômenos naturais biológicos proferidas pelos professores estão frequentemente associadas a uma visão linear e progressista sobre evolução. Isso, por sua vez, não sinaliza necessariamente uma deficiência do processo educacional, mas revela que a escola lida com a síntese de saberes oriundos das esferas científicas (as quais são passíveis de expressar ambiguidades advindas do próprio processo de produção científica) e cotidianas (que se justificam pelo caráter pragmático e econômico das explicações). Nesse sentido, os autores sustentam que a assunção de uma concepção teleológica pelo professor, muitas vezes, está submetida mais às finalidades didáticas (explicações teleológicas entendidas como facilitadoras da aprendizagem) do que ao compromisso com os critérios científicos ou com a discussão das incongruências filosóficas.

Considerando o mesmo raciocínio para o documentário, é presumível que a construção da afirmação "a família sincronizou a procriação para..." exprima o interesse pelo caráter didático da exposição, ainda que com isso negligencie a existência de um universo de tradições epistemológicas distintas que se contraporiam a essa visão. Por isso, a problematização da concepção teleológica assumida pelo documentário poderia, em uma situação em que fosse empregado como recurso didático, desencadear a reflexão sobre as diferentes correntes de pensamento da ciência e a tensão permanente entre a produção científica de conhecimento e os conhecimentos de senso comum. 
Aqui foram levantadas algumas possibilidades de análise de interesse para o currículo de Biologia. Ressalta-se, no entanto, que outras temáticas podem ser exploradas (por exemplo, o sistema de acasalamento monogâmico de albatrozes, a termorregulação e a fisiologia da glândula de sal dos iguanas, entre outros) e outras abordagens de tratamento podem ser assumidas, contanto que sejam alinhadas aos objetivos educacionais do professor e trabalhadas dentro de uma perspectiva crítica e reflexiva do uso do documentário nas aulas.

\section{Vida Animal e Evolução em Explosão de Vida}

Explosão da vida (2005) traz como temática central a Explosão Cambriana, uma expressão utilizada para designar o período em que uma vasta diversidade de filos animais teria aparecido no planeta. O documentário reúne entrevistas com especialistas das áreas de paleontologia, evolução e zoologia, animações e imagens em computação gráfica que ilustram e complexificam as explicações. A narração é feita por uma voz masculina e anônima que conduz de maneira imponente a lógica essencialmente expositiva do filme.

A fronteira entre o ficcional e o não-ficcional é diluída pela adoção de uma narrativa mista. Em muitos momentos, a fauna pré-histórica é qualificada como "criaturas maravilhosas", "estranhas", "fantásticas", "quase irreais" e a ciência apresentada como uma atividade encantadora e estimulante pelo seu caráter de 'desbravamento do desconhecido'. Quanto à lógica informativa, essa se expressa por meio de um conjunto de elementos: a presença de pesquisadores-personagens que outorgam as alegações científicas; a 'voz de Deus' do narrador que veicula informações a respeito do tema no estilo 'mostrado e dito' construído dentro de um modelo de 'solução de problemas'; a mobilização de imagens de arquivos dos fósseis e da natureza 'como ela é'. Dessa forma, o filme concilia o caráter instrutivo e o entretenimento.

O primeiro especialista, o paleontólogo Desmond H. Collins, é introduzido no filme a partir de uma narrativa do tipo 'era uma vez', cuja finalidade aparente é transportar o espectador para um passado interessante, isto é, que tem potencial de explicar a vida no tempo presente. O narrador descreve que "Collins espera lançar uma luz sobre um antigo mistério. No Museu Real de Ontário, em Toronto, ele trabalha com um grande acervo de resquícios de um passado remoto. Fragmentos que revelam um mundo desconhecido até pouco tempo atrás." [voz over do narrador].

As expressões "antigo mistério", "fragmentos que revelam..." denotam que a ciência é tida como uma atividade de 'descoberta', em que o cientista desenvolve estratégias e métodos para desvendar o mundo natural. Frequentemente, os cientistas são mostrados em trabalho de campo na natureza ou em seus laboratórios, o que enaltece a observação e a experimentação como elementos centrais da atividade científica. Tal perspectiva remete a uma visão baconiana do conhecimento, que compreende que a verdade permanece esperando na natureza e ao homem cabe desnudá-la pelo método empírico (DÍAZ; WALDEGG, 2004).

A menção às hipóteses que orientam todo o processo de coleta e análise de dados é feita tanto pelo narrador quanto pelos próprios especialistas: "Pode levar anos e vários recomeços após alarmes falsos para chegar lá. É um jogo de tentativa e erro, como Collins descobriu com o Anomalocaris. Alguns confundiram a garra com um crustáceo ou seguiram outras pistas igualmente equivocadas. Por causa da forma, este espécime foi classificado como uma água-viva. Mas, com novas evidências, as duas hipóteses caíram por terra. Os paleontólogos 
baseiam-se em rochas, mas suas hipóteses nunca podem ser sólidas como elas." [voz over do narrador].

Nesse trecho, um dos aspectos que se destacam é a ideia de que os paleontólogos se 'confundiram' ao fazer determinadas afirmações no passado sobre a espécie em questão, como se suas explicações não estivessem submetidas a uma teoria geral que as suportava. A respeito disso, Bizzo (2013) argumenta que o conhecimento científico é regido por um consenso construído dentro de um meio cultural de determinada época e que se torna vulnerável tanto pela possibilidade de ser falseado quanto pelo fato de cientistas nem sempre estarem dispostos a considerarem explicações para os fenômenos que não sejam compatíveis às suas. Portanto, o autor alega que é imprescindível que se tome a mudança como inerente à iniciativa científica, pois os paradigmas científicos mudam com o tempo.

Quanto à ausência de referência à teoria, Díaz e Waldegg (2004) afirmam que essa visão se trata de um empirismo ingênuo. Nela se considera que observações permitem estabelecer teorias parciais e provisórias que explicam algum fenômeno do universo. Frente a novas observações e experimentos, essas teorias podem ser substituídas por outras que melhor expliquem a realidade. Também a dúvida posta na afirmação de que 'as hipóteses científicas nunca podem ser sólidas como as rochas' indicaria a presença de algum traço falsificacionista, exceto pelo fato de que, no falsificacionismo, a observação é guiada pela teoria e a pressupõe, ainda que essa seja especulativa e deva ser posta à prova, pois, para o falsificacionista, "[...] a ciência progride por tentativa e erro, por conjecturas e refutações" (CHALMERS, 1993, p. 64).

Stocking (2005) afirma que, enquanto cientistas tendem a valorizar mais o processo de produção do conhecimento científico na divulgação dos resultados de suas pesquisas, as mídias dão maior ênfase ao produto final. No documentário, isso se expressa quando o narrador certifica a validade de um conhecimento após um dos pesquisadores confessar seu receio em lidar com hipóteses iniciais que não se confirmam.

Em relação à imagem do cientista e de seu trabalho, o filme veicula a ideia de um profissional essencialmente expedicionário e curioso utilizando as falas dos próprios pesquisadores:"Desde menino, eu tinhafascínio pordinossauros e criaturas primitivas. No $2^{\circ} \mathrm{grau}$, trabalhei como voluntário num museu e ficava impressionado com a capacidade de transformar dados em reconstituições de ecossistemas." [voz de Rudolf A. Raff]; "O que mais gosto de fazer é ir a campo e meter-me na lama com eles. Mesmo que esteja chovendo ou seja de madrugada, não importa. Eu gosto de estar com as minhocas em seu habitat, conhecê-las, compreender como vivem, com que outros animais convivem, quantas são." [voz de Damhnait McHugh].

Martinez (2016) alerta quea visão da'ciência como missão'e de que'ciência sefaz poramor' podem corroborar para a manutenção de uma imagem estereotipada que, ao menos do ponto de vista da educação em Ciências, tem sido tomada como uma perspectiva a ser combatida.

A segunda metade do documentário assume o discurso da responsabilização do homem como 'guardião' da biodiversidade através da voz da pesquisadora que estuda o grupo dos anelídeos. A partir desse momento é introduzida uma retórica preservacionista cujo argumento principal evocado é a importância ecológica que esses animais tiveram e têm para o planeta: "Temos de lembrar que mesmo de criaturas como os anelídeos, mesmo desses grupos, somos dependentes. Dependemos de sua diversidade e do papel que têm nos ecossistemas terrestres e também marinhos. Deveríamos nos considerar guardiões da diversidade de espécies e lembrar que não estamos acima de qualquer uma delas. A verdade é que dependemos muito da diversidade de animais à nossa volta. Até da simples minhoca." [voz de Damhnait McHugh]. 
Empregando afirmações do tipo "Sem os anelídeos, a Terra poderia ser bem diferente e um lugar menos hospitaleiro" [voz over do narrador], percebe-se que o discurso se fundamenta em uma história contrafatual, isto é, em uma história que não ocorreu (uma vez que anelídeos existem). Esse tipo de lógica, explica Brzozowski (2006), sustenta a tese das contingências, do biólogo Stephen J. Gould, que propõe que eventos externos à lógica interna do processo evolutivo podem promover grandes reviravoltas no predomínio de determinados grupos taxonômicos. Supondo uma leitura contrária a do documentário, que considerasse que mesmo sem os anelídeos a Terra ainda assim viria a se tornar um lugar habitável, compreendemos como se torna uma tarefa arriscada conjecturar sobre o passado e o futuro da história evolutiva.

Considerando a possibilidade de uso de Explosão da vida (2005) como recurso didático, a Evolução, a Zoologia/Taxonomia zoológica e a Ecologia são áreas que se destacam no filme. Aqui, apenas são ressaltados alguns aspectos das temáticas que poderiam ser explorados em aula. Por exemplo, a exibição da intersecção entre a paleontologia e a arte para construir modelos de espécies fósseis a partir dos fragmentos coletados por pesquisadores poderia fomentar o debate sobre como, a partir do registro fóssil, é possível elaborar hipóteses sobre como poderia ter sido a vida em tempos remotos e como os registros fósseis se constituem como evidências de evolução.

O documentário também explora, na maior parte do tempo, a biodiversidade animal dentro de abordagem histórico-evolutiva. No entanto, a ordem de apresentação dos filos Porifera, Cnidaria e Platyhelminthes e a ênfase na descrição de seus caracteres morfológicos e fisiológicos denota, em alguma medida, um compromisso com uma abordagem tipológica/ essencialista ancorada numa visão aristotélica de classificação. É notável que, em certo momento, também os anelídeos sejam caracterizados seguindo essa mesma orientação: “ $O$ desenho dos anelídeos é elegante por ser simples e eficiente. Um corpo flexível e segmentado com músculos poderosos, um tubo digestivo da cabeça à cauda, um sistema nervoso sofisticado e um sistema circulatório, funcionando por pulsação. Isso formou um ser capaz de cavar fundo os sedimentos." [voz over do narrador].

Tal perspectiva também reside até os dias de hoje no ensino de zoologia e botânica (AMORIM, 2008) e nos livros didáticos de Ciências e Biologia (CARDOSO-SILVA; OLIVEIRA, 2013; COUTINHO; TEMP; BARTHOLOMEI-SANTOS, 2013). No entanto, Amorim (2008) adverte que é premente que a história evolutiva seja valorizada em detrimento da caracterização morfológica e comportamental dos grupos taxonômicos.

Assim como Nascido do fogo (2004), Explosão da vida (2005) também expressa um cunho teleológico em algumas de suas explicações sobre o surgimento de estruturas corporais nos animais: "Num degrau mais abaixo da cadeia alimentar, outro predador dominava os mares: o Opabinia tinha cinco olhos no alto da cabeça e garras prontas para atacar os fracos e descuidados. Diante de predadores tão ferozes, os animais desenvolveram defesas. O Canadia, um verme, espalhou cerdas pelas laterais de seu corpo. Ter essa armadura era essencial para uma criatura tão lenta. Os Wiwaxias também viviam no leito e tinham ferrões para se proteger".

Nesse caso, ao menos duas hipóteses podem ser sugeridas: a abdicação do conceito de seleção natural se dá em função do didatismo que a teleologia oferece ou o documentário defende explicitamente uma visão adaptacionista do processo evolutivo 
Novamente considerando que esses documentários possam ser incorporados às aulas de Biologia, é fundamental que se observe e se discuta se a narrativa apresentada reforça uma noção de evolução progressiva e direcional, a fim de que essa questão não comprometa o entendimento e a aplicação dos princípios da teoria evolutiva atual.

Como visto até aqui, a complexidade do ensino de muitos conceitos biológicos - a exemplo do ensino de conceitos evolutivos - exige que os professores se atentem ao uso de recursos midiáticos que, enquanto potenciais ferramentas para o processo de aprendizagem, não dispensam a análise crítica do professor que irá mobilizá-los.

\section{Considerações Finais}

O documentário, termo introduzido em 1926 pelo sociólogo escocês John Grierson em um artigo para o jornal The New York Sun, foi proposto como um gênero que fazia 'tratamento criativo da realidade' (CARMO-ROLDÃO; BAZI; OLIVEIRA, 2007). Segundo Jesus (2008, p. 236), Grierson considerava que o cinema documental deveria fortalecer a educação formal tradicional, pois a ideia de transparência subjacente aos documentários era garantida pela "interpretação da realidade documentada pelas grandes narrativas da ciência."

O aparente comprometimento do documentário clássico, também chamado de modo expositivo de representação na tipologia de Nichols (2005), com a ação humana de produção e transmissão do conhecimento fez com que esse gênero cinematográfico fosse prontamente absorvido para finalidades pedagógicas. No entanto, na visão do produtor de documentários Giba Assis Brasil, o que hoje se tem denominado de documentários 'científicos', 'didáticos' ou 'educativos', cuja identificação se faz pelo papel que cumprem ao servir de material para a aprendizagem de algo, tem limitado a percepção dos documentários como possibilidade de expressão e, portanto, de arte (GREGOLIN, SACRINI; TOMBA, 2002).

Particularmente para o ensino de Ciências, alguns autores (BARBOSA; BAZZO, 2013; ÚBEDA, 2009) têm apontado para a pertinência do uso de documentários científicos de ampla difusão para a promoção de reflexões dentro de uma abordagem dos estudos Ciência-Tecnologia-Sociedade-Ambiente (CTSA), reconhecendo o papel desses para a educação científica no âmbito da educação não formal.

Embora em consonância com as perspectivas de que a linguagem audiovisual dos documentários podem se constituir como uma experiência estética e formativa em si e, ao mesmo tempo, servir aos propósitos da aprendizagem mais sistemática almejados pela educação formal, buscamos neste artigo somar a essa discussão aspectos que problematizam as concepções de 'ciência' e 'natureza' presentes nos documentários 'científicos'.

Como argumentado ao longo do texto, a predominância do modo expositivo de representação nos documentários sobre natureza, a exemplo de Nascido do fogo (2004) e Explosão da vida (2005), reforçam uma visão idealista de representação do mundo ao pretender objetividade com o afastamento do sujeito (documentarista) que observa os fenômenos e ao crer que o conhecimento científico (mediado pelo narrador em voz over ou pelos cientistas-personagens) traduz fidedignamente a realidade. Ademais, a 'natureza' é tida como um enigma a ser 'revelado', 'descoberto' pelos cientistas, que, ao tomarem como seu objeto de pesquisa a natureza 'nua e crua', eliminam toda referência ao humano e às finalidades humanas; são, pois, as 'ciências naturais' (FOUREZ, 2003) 
Considerando que há algumas décadas a relação entre ciência e sociedade tem favorecido a entrada dos estudos da História e Filosofia da Ciência nos currículos de Ciências (KRASILCHIK, 2000), hoje já se consolida a importância do debate sobre os aspectos da Natureza da Ciência ( $\mathrm{NdC})$.

McComas, Almazroa e Clough (1998, p. 513, tradução de EL-HANI, 2006, p. 5-6) elencam uma série de características da NdC que deveriam ser abordadas na educação científica:

(i) o conhecimento científico, embora robusto, tem uma natureza conjectural;

(ii) o conhecimento científico depende fortemente, mas não inteiramente, da observação, da evidência experimental, de argumentos racionais e do ceticismo;

(iii) não há uma maneira única de fazer ciência, isto é, não há um método científico universal, a ser seguido rigidamente;

(iv) a ciência é uma tentativa de explicar fenômenos naturais;

(v) leis e teorias cumprem papéis distintos na ciência, e teorias não se tornam leis, mesmo quando evidências adicionais se tornam disponíveis;

(vi) pessoas de todas as culturas contribuem para ciência;

(vii) novos conhecimentos devem ser relatados aberta e claramente;

(viii) a construção do conhecimento científico requer registros de dados acurados, crítica constante das evidências, das teorias, dos argumentos etc. pelas comunidades de pesquisadores, e replicação dos estudos realizados;

(ix) observações são dependentes de teorias, de modo que não faz sentido pensarse em uma coleta de dados livre de influências e expectativas teóricas;

(x) cientistas são criativos;

(xi) a história da ciência apresenta um caráter tanto evolutivo quanto revolucionário;

(xii) a ciência é parte de tradições sociais e culturais;

(xiii) a ciência e a tecnologia impactam uma à outra;

(xiv) ideias científicas são afetadas pelo meio social e histórico no qual são construídas.

Gil-Pérez et al. (2001) e El-Hani (2006) consideram que construir concepções epistemológicas que contemplem os aspectos expostos acima é uma tarefa do ensino de Ciências, principalmente porque a visão mais comumente difundida pela opinião pública e pela mídia ainda está assentada sobre um ideário empírico-indutivista. Nesse sentido, compete à educação formal em Ciências analisar e confrontar as distintas perspectivas que contribuem para a construção sobre o imaginário científico nos estudantes.

Em suma, buscou-se apresentar neste trabalho uma análise de dois documentários a fim de discutir as possibilidades e os limites do uso desse tipo de produção no ensino de Biologia. Contudo, cabe ressaltar que as leituras aqui expostas devem ser tomadas em sua provisoriedade e inacabamento, uma vez que outros olhares são possíveis e desejáveis.

Como sublinha Brennand (2008), a escola deve lidar com as diferentes linguagens e os professores devem ser formados para trabalhar com todas elas. Também aqui se manifesta concordância com a autora quando afirma que a linguagem audiovisual pode estimular o sistema afetivo-avaliativo dos educandos, a expressão da subjetividade, da capacidade crítica e estética.

Todavia, a introdução dessas e de outras mídias na prática pedagógica deve sempre se respaldar numa perspectiva crítica e analítica, evitando que sejam empregadas como ferramentas meramente ilustrativas das disciplinas escolares.

No caso do ensino de Biologia, a literatura aponta que poucos estudos se debruçam sobre como filmes são incorporados à dinâmica das aulas, ainda que se ateste ser antiga a 
presença desse tipo de mídia nas escola. E, frequentemente, para as disciplinas relacionadas às Ciências da Natureza, são recomendados filmes documentais que abordam o mundo natural do ponto de vista da ciência, o que nos impele à necessária avaliação sobre as visões de ciência e natureza que estão sendo veiculadas

Aqui, intentou-se salientar que, se por um lado, documentários desse gênero tendem a realizar uma leitura ingênua e objetivista da ciência, por outro, podem fomentar discussões mais profundas sobre a natureza da ciência $(\mathrm{NdC})$ e favorecer a aprendizagem em temas biológicos de modo geral, contribuindo assim para uma formação mais problematizadora e reflexiva.

Sabendo-se que é crescente a produção de documentários sobre a natureza na indústria cinematográfica, muitos dos quais carregam explicitamente finalidades educativas, sugere-se que esse tipo de estudo seja ampliado a fim de que professores possam tomá-lo como um referencial para o aprimoramento de sua prática pedagógica com relação ao uso da linguagem audiovisual.

\section{Referências}

AMORIM, D. S. Paradigmas pré-evolucionistas, espécies ancestrais e ensino de zoologia e botânica. Ciência \& Ambiente, Santa Maria, v. 19, n. 36, p. 125-150, 2008.

AZEVEDO, M.; AYRES, A. C. M.; SELLES, S. E. Explicações teleológicas no ensino de evolução. Enseñanza de las Ciencias, Barcelona, num. ext., p. 229-234, 2013.

BARBOSA, L. C. A.; BAZZO, W. A. O uso de documentários para o debate ciência-tecnologiasociedade (CTS) em sala de aula. Ensaio, Belo Horizonte, v. 15, n. 3, p. 149-161, 2013. DOI: https:// doi.org/10.1590/1983-21172013150309

BARDIN, L. Análise de conteúdo. São Paulo: Edições 70, 2016.

BIZZO, N. História da ciência e ensino da ciência: instrumentos para a prática e a pesquisa escolar. In: ARANTES, V. A. Ensino de ciências: pontos e contrapontos. São Paulo: Summus, 2013. p. 13-59.

BONOTTO, A. Bill Nichols fala sobre documentário: vozes e reconstituições. DOC On-line: revista digital de cinema documentário, Campinas, Covilhã, n. 6, p. 250-263, 2009.

BORBA, B. A. Documentários de natureza: um panorama a partir dos estudos culturais. In: SEMINÁRIO BRASILEIRO DE ESTUDOS CULTURAIS E EDUCAÇÃO, 7., 2017, Porto Alegre. Anais [...] Porto Alegre: UFRGS, 2017. p. 1-14.

BRASIL. Presidência da República. Lei no 9.394, de 20 de dez. de 1996. [Diário Oficial da União], Brasília, 23 dez. 1996.

BRASIL. Presidência da República. Lei no 13.006, de 26 de junho de 2014. [Diário Oficial da União], Brasília, 27 jun. 2014.

BRENNAND, E. G. G. Tecendo fios e desafios na construção de saberes mediados pelas tecnologias da informação e da comunicação. In: PEREIRA, M. G.; AMORIM, A. C. R. (org.). Ensino de biologia: fios e desafios na construção de saberes. João Pessoa: Ed..UFPB, 2008. p. 83-101.

BRUZZO, C. O documentário em sala de aula. Ciência \& Ensino, Piracicaba, n. 4, p. 23-25, 1998. 
BRZOZOWSKI, J. A. O neo-darwinismo frente às teses da auto-organização e das contingências. In: PRESTES, M. E. B.; MARTINS, L. A-C. P.; STEFANO, W. Filosofia e história da biologia 1. São Paulo: MackPesquisa, 2006. p. 147-160.

CARDOSO-SILVA, C. B.; OLIVEIRA, A. C. Como os livros didáticos de biologia abordam as diferentes formas de estimar a biodiversidade? Ciência \& Educação, Bauru, v. 19, n. 1, p. 169-180, 2013. DOI: https://doi.org/10.1590/S1516-73132013000100012

CARMO-ROLDÃO, I. C.; BAZI, R. E. R.; OLIVEIRA, A. P. S. O espaço do documentário e da vídeoreportagem na televisão brasileira: uma contribuição ao debate. Contracampo, Niterói, n. 17, p. 107-125, 2007.

CARVALHO, M. O documentário e a prática jornalística. PJ:Br: jornalismo brasileiro, n. 7, 2006. Disponível em: http://www2.eca.usp.br/pjbr/arquivos/ensaios7_d.htm. Acesso em: 3 fev. 2019.

CHALMERS, A. F. O que é ciência, afinal? São Paulo: Brasiliense, 1993.

COUTINHO, C.; TEMP, D. S.; BARTHOLOMEI-SANTOS, M. L. Relação entre diversidade animal e evolução nos livros didáticos de ciências e biologia. In: ENCONTRO REGIONAL SUL DE ENSINO DE BIOLOGIA, 6., 2013, Santo Ângelo. Anais [...] Santo Ângelo: URI, 2013, p. 1-14.

DÍAZ, V. G.; WALDEGG, G. Ciencia y cientificidad en la televisión educativa. Enseñanza de las Ciencias, Barcelona, v. 22, n. 1, p. 147-158, 2004.

EL-HANI, C. N. Notas sobre o ensino de história e filosofia das ciências na educação científica de nível superior. In: SILVA, C. C. (org.). História e filosofia da ciência no ensino de ciências: da teoria à sala de aula. São Paulo: Livraria da Física, 2006. p. 3-21.

EXPLOSÃO da vida. Produção de David Elisco. Washington: National Geographic, 2005. 1 DVD (53 min), son., color. [Coleção] Origens da vida, 4.

FOUREZ, G. Crise no ensino de ciências? Investigações em Ensino de Ciências, Porto Alegre, v. 8, n. 2, p. 109-123, 2003.

GIL-PÉREZ, D.; MONTORO, I. F.; ALÍS, J. C.; CACHAPUZ, A.; PRAIA, J. Para uma imagem não deformada do trabalho científico. Ciência \& Educação, Bauru, v. 7, n. 2, p. 125-153, 2001. DOI: https://doi. org/10.1590/S1516-73132001000200001

GREGOLIN, M. V.; SACRINI, M.; TOMBA, R. A. Web-documentário: uma ferramenta pedagógica para o mundo contemporâneo. 2002. 120 f. Trabalho de Conclusão de Curso (Graduação em Comunicação Social) - Faculdade de Jornalismo, Pontifícia Universidade Católica de Campinas, Campinas, 2002.

JESUS, R. M. V. Escola e documentário: uma relação antiga. Revista HISTEDBR On-line, Campinas, n. 32, p. 233-242, 2008.

KRASILCHIK, M. Reformas e realidade: o caso do ensino de ciências. São Paulo em Perspectiva, São Paulo, v. 14, n. 1, p. 85-93, 2000. DOI: https://doi.org/10.1590/S0102-88392000000100010

McCOMAS, W. F.; ALMAZROA, H.; CLOUGH, M. P. The nature of science in science education: an introduction. Science \& Education, Dordrecht, v. 7, p. 511-532, 1998. DOI: https://doi. org/10.1023/A:1008642510402

MARCELLO, F. A.; RIPOLL, D. A educação ambiental pelas lentes do cinema documentário. Ciência \& Educação, Bauru, v. 22, n. 4, 1045-1062, 2016. DOI: https://doi.org/10.1590/1516-731320160040013 
MARCELLO, F. A. Real versus ficção: criança, imagem e regimes de credibilidade no cinemadocumentário. Educação em Revista, Belo Horizonte, v. 26, n. 3, p. 129-150, 2010. DOI: https://doi. org/10.1590/S0102-46982010000300007

MARTINEZ, M. A imagem do cientista no imaginário contemporâneo: o caso do Instituto Royal. Rizoma, Santa Cruz do Sul, v. 4, n. 2, p. 122-137, 2016.

MINAYO, M. C. S. Desafio do conhecimento: pesquisa qualitativa em saúde. São Paulo: Hucitec, 2010.

MOLFETTA, A. Linguagem, ética e política no documentário da América Latina. Salto para o Futuro, Rio de Janeiro, ano 18, bol. 11, p. 19-24, 2008.

MORAES, A. C. R. Geografia histórica do Brasil: capitalismo, território e periferia. São Paulo: Annablume, 2001.

NAPOLITANO, M. Cinema: experiência cultural e escolar. In: SÃO PAULO (Estado). Secretaria da Educação. Caderno de cinema do professor: dois. São Paulo: FDE, 2009. p. 10-31.

NASCIDO do fogo. Produção: Patrick Morris. London: British Corporation Company, 2004. 1 DVD (49 min), son., color. [Série] Galápagos, 1.

NICHOLS, B. Introdução ao documentário. São Paulo: Papirus, 2005.

REZENDE, L. Como analisar um documentário?: questões estéticas e éticas. Salto para o Futuro, Rio de Janeiro, ano 18, bol. 11, p. 25-29, 2008.

RICKLEFS, R. E. Economia da natureza. 6 ed. Rio de Janeiro: Guanabara Koogan, 2010.

SÃO PAULO (Estado). Secretaria da Educação. Caderno de cinema do professor: um. São Paulo: FDE, 2008.

STOCKING, S. H. Como os jornalistas lidam com as incertezas científicas. In: MASSARANI, L.; TURNEY, J.; MOREIRA, I. C. (org.). Terra incógnita: a interface entre ciência e público. Rio de Janeiro: Vieira \& Lent, 2005. p. 161-182.

TEIXEIRA, P. M. M.; MEGID NETO, J. O estado da arte da pesquisa em ensino de biologia no Brasil: um panorama baseado na análise de dissertações e teses. Revista Electrónica de Enseñanza de las Ciencias, Vigo, v. 11, n. 2, 273-297, 2012.

TORRES, E. C. O recurso à ficção em dois filmes documentais portugueses. In: BORGES, G.; PUCCI JR, R. L.; SELIGMAN, F. (ed.). Televisão: formas audiovisuais de ficção e de documentário. Faro: Edições CIAC; São Paulo: SOCINE, 2011. v. 1, p. 27-37.

TUCHERMAN, I.; RIBEIRO, M. S. Ciência e mídia: negociações e tensões. Eco-Pós, Rio de Janeiro, v. 9, n. 1, p. 246-262, 2006.

ÚBEDA, J. S. Los documentales científicos como instrumentos de formación ciudadana para hacer frente a la situación de emergencia planetaria. Enseñanza de las Ciencias, Barcelona, núm. extra, p. 113-116, 2009.

VILELA, M. L.; GOMES, M. M.; CASSAB, M.; AZEVEDO, M. Conhecimentos escolares de biologia: investigando seleções e mediação didáticas de professores. In: SELLES, S. E.; CASSAB, M. (org.). Currículo, docência e cultura. Niterói: Eduff, 2012. p. 99-118. 